JAMA Surgery | Review

\title{
Characteristics of Early-Onset vs Late-Onset Colorectal Cancer
} A Review

REACCT Collaborative

IMPORTANCE The incidence of early-onset colorectal cancer (younger than 50 years) is rising globally, the reasons for which are unclear. It appears to represent a unique disease process with different clinical, pathological, and molecular characteristics compared with late-onset colorectal cancer. Data on oncological outcomes are limited, and sensitivity to conventional neoadjuvant and adjuvant therapy regimens appear to be unknown. The purpose of this review is to summarize the available literature on early-onset colorectal cancer.

OBSERVATIONS Within the next decade, it is estimated that 1 in 10 colon cancers and 1 in 4 rectal cancers will be diagnosed in adults younger than 50 years. Potential risk factors include a Westernized diet, obesity, antibiotic usage, and alterations in the gut microbiome. Although genetic predisposition plays a role, most cases are sporadic. The full spectrum of germline and somatic sequence variations implicated remains unknown. Younger patients typically present with descending colonic or rectal cancer, advanced disease stage, and unfavorable histopathological features. Despite being more likely to receive neoadjuvant and adjuvant therapy, patients with early-onset disease demonstrate comparable oncological outcomes with their older counterparts.

CONCLUSIONS AND RELEVANCE The clinicopathological features, underlying molecular profiles, and drivers of early-onset colorectal cancer differ from those of late-onset disease. Standardized, age-specific preventive, screening, diagnostic, and therapeutic strategies are required to optimize outcomes.

JAMA Surg. 2021;156(9):865-874. doi:10.1001/jamasurg.2021.2380

Published online June 30, 2021. Corrected on August 11, 2021.
Group Information: The REACCT Collaborative Authors appear at the end of this article.

Corresponding Author: Alexandra M. Zaborowski, MD, Centre for Colorectal Disease, St Vincent's University Hospital, Elm Park, Dublin 4, Ireland (zaborowa@tcd.ie).
A Ithough the overall incidence of colorectal cancer (CRC) has decreased globally, the incidence in younger adults (defined as disease presenting in a patient younger than 50 years) is rising alarmingly. The reasons for this disproportionate increase are unknown, in part because of a lack of robust epidemiological data internationally. While genetic predisposition plays a role, the minority of cases occur in the context of a known hereditary cancer syndrome. Environmental risk factors alone do not explain the observed trends, because they are not associated with age. The clinicopathological and molecular landscape of earlyonset CRC (EOCRC) displays considerable heterogeneity. Presentation at an advanced disease stage and unfavorable histopathological features are more common in younger individuals. The oncotherapeutic sensitivity of EOCRC is unclear, with survival data lacking and conflicting. Despite the appearance of a biomolecularly unique disease process, age at diagnosis is not considered in modern treatment strategies. Unravelling the causative mechanisms and full spectrum of germline sequence variations and somatic molecular profiles of EOCRC will be key toward disease prevention, thereby allowing individualized treatment in this patient population.

\section{Methods}

A literature review was performed to summarize the epidemiology, causative mechanisms, clinicopathological features, and oncological outcomes of EOCRC. PubMed, Scopus, and Embase databases were searched for articles published in English that included patients with colorectal cancer younger than 50 years. The search took place from July 2020 to March 2021. There was no restriction on the date of publication.

\section{Results}

\section{Definition}

There is currently no clear and internationally accepted definition of EOCRC. Published studies reporting on the subject use varying cutoff ages, hampering the interpretation and applicability of findings. An age younger than 50 years at diagnosis is generally considered EOCRC, because this is the age at which most national screening programs commence. Furthermore, dichotomization by age using an arbitrary integer cutoff represents a considerable limitation. Significant variation in clinicopathological features and oncological 
outcomes has been observed among patients younger than 50 years, suggesting the need for further age-based subgrouping. ${ }^{1}$

\section{Epidemiology}

Although the implementation of population-based screening has reduced the overall incidence of CRC, there has been an increase in incidence among young adults younger than 50 years. Recent data from large European registry-based studies ${ }^{2,3}$ indicate that CRC rates have increased dramatically among patients aged 20 to 49 years over the last 25 years. In particular, there has been a rise in cancers of the distal colon and rectum. Rectal cancer rates increased by $1.8 \%$ per year from 1990 to 2016, with the greatest annual percentage change (3.5\%) among adults aged 20 to 29 years. ${ }^{2}$ Similar trends have been observed in the US, Australia, and Asia. ${ }^{4,5}$ Early-onset CRC accounts for 1 in 10 CRC diagnoses, representing the second most common cancer and the third leading cause of cancer-associated death in this age group. ${ }^{6}$ Based on current data, it is estimated that the incidence rates of colon and rectal cancer will increase by $90 \%$ and $124 \%$, respectively, among adults aged 20 to 34 years and $27 \%$ and $46 \%$, respectively, for those aged 35 to 49 years within the next decade. ${ }^{4}$ By 2030, 1 in 10 colon cancers and 1 in 4 rectal cancers will be diagnosed in individuals younger than 50 years. ${ }^{4}$ Although improved reporting may account in part for increased incidence, EOCRC is a global phenomenon observed in many countries with a history of population-based screening and incidence reporting. Among 5 major US racial/ethnic groups (Non-Hispanic White, Non-Hispanic Black, Hispanic, Asian American, and Pacific Islander), the greatest increase in incidence of CRC has been observed in non-Hispanic White men and women and Hispanic men, predominantly driven by rectal cancer. ${ }^{7,8}$ There has also been a significant increase in rectal cancer among Black men and women. ${ }^{9}$ Reasons for this racial/ ethnic disparity are complex and may in part be associated with lifestyle factors, socioeconomic status, and access to health care.

\section{Clinical Features}

The clinical features of EOCRC differ from those of late-onset disease. Early-onset tumors typically occur in the distal colon and rectum. ${ }^{7,10,11}$ North American data provided by the Surveillance, Epidemiology, and End Results (SEER) database found that among men and women, $41 \%$ and $36 \%$ of tumors were located in the rectum, respectively, while $26 \%$ and $25 \%$, respectively, were in the proximal colon. ${ }^{12}$ The anatomical location of EOCRC may provide important insights into the underlying causative mechanisms, disease processes, and treatment responses of such cancers, since there is increasing evidence that ascending colon cancers differ biologically from descending colon and rectal cancers. Ascending tumors are associated with old age, advanced stage, and female sex..$^{13,14}$ They are often bulky, exophytic, polypoid lesions growing into the colonic lumen and may present with iron-deficiency anemia, while descending tumors tend to present as infiltrating, constricting lesions encircling the lumen and causing obstructive symptoms. ${ }^{15,16}$ Higher rates of lymph node involvement, lymphovascular invasion, and poorer oncologic outcomes have also been observed with tumors in the ascending colon compared with tumors in the descending colon. ${ }^{14,15}$

Younger patients with CRC are more likely to have synchronous and metachronous lesions and typically display more advanced disease stage at presentation compared with their older counterparts. ${ }^{10,17}$ Several large population-based studies ${ }^{18-21}$ have shown a worryingly high proportion of stage 3 and 4 disease, ranging between $54 \%$ and $61.8 \%$. Younger patients were more likely to present with regional disease (relative risk ratio, 1.37 [95\% Cl, 1.341.41]; $P<.001$ ) or distant disease (relative risk ratio, $1.58[95 \% \mathrm{Cl}$, 1.53-1.63]; $P<.001$ ) than their older counterparts. ${ }^{22}$ Although population-based screening may account for earlier disease stage at diagnosis in older patients, both patient-associated and physicianassociated factors may delay evaluation of symptoms, contributing to the later stage at diagnosis observed among young individuals. Low suspicion of cancer, lack of knowledge about the disease, or failure to recognize concerning symptoms may all lead to delayed evaluation, reported to be a mean of 6.2 months. ${ }^{23}$ Symptoms may also overlap with those of more common benign diagnoses. Physician-associated delay in diagnosis has been reported to range between $15 \%$ and $50 \% .{ }^{23}$ In a study of 1025 patients, ${ }^{24} 886$ (86.4\%) were symptomatic at diagnosis. Patients with rectal cancer were more likely to be symptomatic than those with colon cancer $(449$ of 499 [90.0\%] vs 435 of 524 [83.0\%]; $P<.001)$. Of those who were asymptomatic, investigations were performed in 139 because of the presence of anemia in 19 (13.7\%), a positive fecal occult blood test result in 10 (7.2\%), an abdominal mass in 3 (2.2\%), a mass on a digital rectal examination in 3 (2.2\%), and other reasons in 110 (79.1\%). In another study of 1514 patients with rectal cancer, the median time from symptom onset to treatment was 217 days among those younger than 50 years, compared with 29.5 days for those older than 50 years. ${ }^{25}$ These data highlight the importance of considering CRC as a potential diagnosis in adults younger than 50 years (regardless of family history). Notably, given that most patients are symptomatic and have sporadic disease, emphasis should also be placed on education and not only on screening strategies. Educational initiatives to raise awareness among young adults, primary care physicians, and clinicians are imperative to ensure timely diagnosis and intervention.

\section{Pathological Features}

Early-onset CRCs more frequently display adverse histopathological features. Poor differentiation, perineural invasion, venous invasion, and mucinous and/or signet cell morphology, all of which are suggestive of an unfavorable tumor biology and associated with worse oncological outcomes, are more common among patients with EOCRC. ${ }^{26}$ In a review ${ }^{19}$ of data from the SEER database (19911999), 1334 patients with colon cancer aged 20 to 40 years were compared with 46457 patients aged 60 to 80 years. Younger patients were significantly more likely to present with poorly differentiated (364 of 1334 [27.3\%] vs 7991 of 46457 [17.2\%]; $P<.001$ ) or anaplastic disease (21 of 1334 [1.6\%] vs 325 of 46457 [0.7\%]; $P<.001)$ than their older counterparts. ${ }^{19}$ They also had more mucinous and signet-ring tumors than the older group (209 of 1334 [15.7\%] vs 5343 of 46457 [11.5\%]; $P<.001 ; 51$ of 1334 [3.8\%] vs 372 of 46457 [0.8\%]; $P<.001) .{ }^{19}$ Similarly, an analysis ${ }^{18}$ of 64068 patients with early-onset CRCs (younger than 50 years) and 524801 patients with later-onset CRCs (50 years or older) using the North American National Cancer Database found that younger patients more frequently displayed poor or no differentiation $(20.4 \%$ vs $18 \% ; P<.001)$ and mucinous and signet-ring morphology $(12.6 \%$ vs $10.8 \% ; P<.001)$. The mucinous subtype of CRC represents a negative prognostic indicator, associated with poorer 
response to neoadjuvant chemoradiotherapy, higher rates of positive margins, and worse survival compared with nonmucinous tumors. 27,28

\section{Molecular Profile}

There is a growing body of evidence to suggest that EOCRC may represent a unique disease process, characterized by distinct biomolecular features and oncogenic aberrations or alterations. Numerous studies have attempted to define the molecular landscape of sporadic EOCRC, and while overlapping key drivers are implicated in both early-onset and late-onset disease, there appear to be several notable differences. Overall, younger patients typically have microsatellite stable tumors and more frequently exhibit long interspersed nuclear elements (LINE-1) hypomethylation and tumor protein 53 (TP53) sequence variations. ${ }^{29}$ They are less likely to harbor K-Ras (KRAS), B-Raf (BRAF) V600E, and adenomatous polyposis coli $(A P C)$ gene sequence variations or display promoter methylation of $\mathrm{CpG}$ islands (Table). ${ }^{10,26,30,31}$

Dichotomization of CRC into microsatellite stable (MSS) disease and disease with microsatellite instability is now recommended routinely for all patients as per the National Comprehensive Cancer Network guidelines. ${ }^{32}$ Subsequent genetic screening for Lynch syndrome (following appropriate counseling and consent) should be performed in patients with loss of mismatch repair proteins MutL homolog 1 (MLH1), MutL homolog 2 (MSH2), mutS homolog 6 (MSH6), and PMS1 homolog 2 (PMS2). ${ }^{33}$ Lynch syndrome occurs as a result of constitutive sequence variations in one of the mismatch repair proteins.

In EOCRC, almost all microsatellite instability tumors are associated with Lynch syndrome and are rarely because of somatic inactivation of $M L H 1 .^{31}$ Notably, significant differences have also been observed between early-onset and late-onset MSS tumors. Gene expression analysis identified catenin beta 1 (CTNNB1) gene as one of the most overexpressed genes in younger patients compared with older patients with MSS-associated disease. ${ }^{34}$ Furthermore, key pathways, such as Wnt/beta catenin, mitogen-activated protein kinase, growth factor signaling (epidermal growth factor receptor, hepatocyte growth factor, and platelet-derived growth factor), and the tumor necrosis factor receptor 1 pathway have also been implicated in sporadic EOCRC. ${ }^{34}$ These pathways, which appear upregulated in early-onset disease, play a critical role in cellular adhesion and motility, apoptosis, and inflammation, which may in part influence metastatic potential and chemoradiosensitivity. Molecular profile has important clinical, prognostic, and therapeutic implications. To that end, subclassification of EOCRC according to genomic signatures has been proposed. ${ }^{35}$

Gene expression-based subtyping has led to the classification of CRC into 4 consensus molecular subtypes (CMS) on the basis of distinguishing molecular characteristics. ${ }^{36} \mathrm{~A}$ retrospective analysis ${ }^{10}$ of patients with CRC younger than 40 years found CMS1 (microsatellite instability with immune infiltration and activation) was the most common subtype (11 of 24 [46\%]), while CMS3 (termed metabolic, with metabolic dysregulation and KRAS sequence variations) and CMS4 (termed mesenchymal, with marked stromal infiltration, transforming growth factor- $\beta$ activation, and angiogenesis) were uncommon (1 of 24 [4\%] and 3 of 24 [13\%], respectively; $P=.003)$. Consensus molecular subtype 2 (termed canonical, with WNT and MYC proto-oncogene [MYC]
Table. Pathological Features and Molecular Profile of Early-Onset Colorectal Cancer

\begin{tabular}{ll}
\hline Pathological features & Molecular profile \\
\hline Poor differentiation & Microsatellite stability \\
\hline Mucinous tumors & $\begin{array}{l}\text { More likely to exhibit LINE-1 hypomethylation } \\
\text { and TP53 sequence variations }\end{array}$ \\
\hline Signet-ring morphology & $\begin{array}{l}\text { Less frequently harbor KRAS, BRAF V600E, } \\
\text { and APC sequence variations }\end{array}$ \\
\hline Perineural/venous invasion & \begin{tabular}{l} 
Promoter methylation of CpG islands \\
\hline
\end{tabular}
\end{tabular}

Abbreviations: $A P C$, adenomatous polyposis coli; $B R A F$, B-Raf; KRAS, K-Ras; LINE-1, long interspersed nuclear elements; TP53, tumor protein 53.

activation) was relatively stable across age groups. Although CMS1 was the most prevalent subtype, most patients with EOCRC have sporadic, microsatellite, stable tumors. The role of the immune system in early-onset disease remains largely undefined. It is plausible that alternative unknown molecular drivers evoke the intratumoral immune response characteristic of CMS1.

\section{Hereditary EOCRC}

A young age at disease onset is a hallmark of an inherited cancer predisposition. The estimated prevalence of hereditary cancer syndromes in EOCRC ranges between 5\% to 35\%, compared with 2\% to $5 \%$ of colorectal cancers overall. ${ }^{26,37-39}$ These syndromes may be subclassified into Lynch syndrome (formerly known as hereditary nonpolyposis colorectal cancer syndrome) or as one of the polyposis syndromes (including familial adenomatous polyposis, attenuated familial adenomatous polyposis, and MutY DNA glycosylase gene $[M U T Y H]$-associated adenomatous polyposis).

Lynch syndrome is the most commonly diagnosed hereditary cancer syndrome implicated in the pathogenesis of EOCRC. ${ }^{39,40}$ The lifetime risk of developing CRC in Lynch syndrome is between $50 \%$ and $70 \%$, and in $40 \%$, the onset of CRC is before age 40 years. ${ }^{41}$ It accounts for approximately one-third of EOCRC in patients younger than 35 years. ${ }^{39,42}$ Data from a multicenter prospective observational study ${ }^{43}$ show that different gene-specific and sex-specific risks of CRC exist in Lynch syndrome, which should be incorporated into modern management guidelines.

Diagnosis of a hereditary cancer syndrome has significant implications for both the patient and their family members. For Lynch syndrome, surgical approach is based on the risk of metachronous $\mathrm{CRC}$, which depends on the variant a carrier has and the management of the primary cancer. Available data on risk of metachronous cancers in this patient group are limited and retrospective, and prospective studies stratified by pathogenic variants are required to determine optimal management. Guidelines from the European Hereditary Tumour Group and European Society of Coloproctology recommend standard segmental resection for a first colonic cancer in individuals carrying MSH6 or PMS2 pathogenic variants, while extended surgery (subtotal colectomy and ileosigmoidal anastomosis or total colectomy and ileorectal anastomosis) is preferable in those who carry $\mathrm{MLH}$ 1 or MSH2 pathogenic variants. ${ }^{33}$ Extended surgery is recommended for a metachronous colonic cancer with previous segmental colectomy, regardless of the pathogenic variant. ${ }^{33}$ For a first rectal cancer, standard resection (anterior resection or abdominoperineal resection) is advised for all variants. ${ }^{33}$ In the case of a synchronous colonic cancer, extended surgery can be considered. All surgical decision-making should be individualized, taking 
into account age, sex, anticipated functional outcome, quality of life, and other personal priorities (eg, fertility).

Since the introduction of multigene panel testing, the spectrum of germline sequence variations predisposing individuals to EOCRC has expanded to include SMAD family member 4 (SMAD4), checkpoint kinase 2 (CHEK2), and DNA polymerase epsilon, catalytic subunit $(P O L E)$ genes, along with gene alterations of uncertain clinical relevance (variants of unknown significance). The development of next-generation sequencing has enabled genetic testing for hereditary CRC to include multiple genes implicated in various hereditary cancer syndromes. Notably, a considerable proportion of patients diagnosed with EOCRC who do not report a positive family history harbor a gene alteration associated with an inherited cancer predisposition. Stoffel et al ${ }^{42}$ found that only half of those with germline sequence variations reported a CRC diagnosis in a first-degree relative. This group of patients at high risk of developing EOCRC would not meet the current criteria for early screening.

\section{The Exposome}

Although inherited predisposition is relevant in EOCRC, it does not explain the observed rise in incidence. Most cases are sporadic and may occur as a result of the exposome (in the absence or presence of a somatic sequence variation). The exposome represents the totality of exposures from conception onwards and may be considered the environmental equivalent of the human genome. ${ }^{44}$ It consists of 3 overlapping domains: the general external environment, specific external environment (eg, diet, smoking, alcohol, infection, antibiotics) and the internal environment (eg, gut microbiota). Exposomal data specific to individuals younger than 50 years are lacking; however, considering what is known about CRC overall will help unravel the potentially unique exposome of EOCRC and determine what drives this disease. To decipher the exposomal elements contributing to EOCRC, several facts about the disease must be considered. Incidence has been increasing for the past 4 decades, with men and women affected. It represents a global phenomenon, is associated with chronic inflammation and dysbiosis, and is not limited to individuals with obesity. ${ }^{2,4,45-48}$ Among the potential factors suggested are a Westernized diet, obesity, antibiotics, infection, and alterations to the gut microbiome.

A Westernized diet, which is high in saturated fat, rich in red meat, and low in fiber, is a well-known risk factor for CRC. ${ }^{49}$ In addition to promoting dysbiosis, this diet generates proinflammatory and procarcinogenic advanced glycation end products. High levels of advanced glycation end products, a high Diet Inflammatory Index score (a measure of the inflammatory potential of a diet), and certain dietary food additives, such as monosodium glutamate and titanium dioxide, both of which promote tumorigenesis in animal models of CRC, may all contribute to development of EOCRC. ${ }^{50}$

Obesity (body mass index [calculated as weight in kilograms divided by height in meters squared] $>30$ ), a well-defined risk factor for CRC later in life, ${ }^{49}$ has also been postulated to drive EOCRC, owing to its global increase, promotion of dysbiosis, and known proinflammatory and procarcinogenic effects. In a prospective cohort study ${ }^{51}$ of 85256 women, those with obesity had a nearly doubled risk of EOCRC compared with those with a normal body mass index. Notably, the association between obesity appears stronger for colon cancer than rectal cancer, which is important because the observed increase in EOCRC is predominantly because of an increase in rectal cancer incidence. ${ }^{52} \mathrm{~A}$ recent meta-analysis found an association between childhood and adolescent obesity and colon cancer but not rectal cancer. ${ }^{48}$

An association between antibiotic use and CRC has been demonstrated in several epidemiological studies. ${ }^{53,54}$ Exposure during pregnancy or childhood may lead to remodeling of the gut microbiota toward an oncogenic phenotype. Human data, however, are lacking, while those from animal models are conflicting. Although some studies involving murine models suggest antibiotic use can promote $\mathrm{CRC}$, others found the elimination of specific bacteria with antibiotic therapy to be protective. ${ }^{55,56}$

Data from in vitro, murine, and cross-sectional human studies suggest that the gut microbiome is involved in the etiopathogenesis of CRC. Dysbiosis transforms a health-promoting microbiome of commensals and mutualists into a proinflammatory and procarcinogenic environment characterized by parasitism and amensalism. ${ }^{57,58}$ Bacteroides fragilis, Escherichia coli, and Fusobacterium nucleatum have been identified as key organisms in colon carcinogenesis. ${ }^{59}$ In addition to directly promoting CRC, the microbiome may also mediate the effects of diet and obesity. Changes in gut microbiome influence host metabolism, with murine data ${ }^{60}$ suggesting that Firmicutes and Bacteroidetes mediate insulin resistance through modulation of glucagon-like peptide-1 secretion in obesity. It is plausible that an altered gut microbiome (eg, because of obesity in childhood or adolescence) may influence gene expression patterns and the immune microenvironment of the gastrointestinal tract, rendering it susceptible to carcinogenesis in early adulthood.

Understanding the causal association between potentially modifiable risk factors and CRC and the proportion of cases and deaths attributable (ie, population attributable fraction [PAF]) is key to implementing effective preventive strategies. The estimated PAF for categorical exposure variables can be calculated using exposure prevalence and corresponding relative risk. An analysis ${ }^{61}$ of 1570975 incident cancers across 26 cancer types in adults older than 30 years found the proportion of CRC cases caused by potentially modifiable risk factors was $54.6 \%$. Colorectal cancer had the second highest number of cancer cases or deaths attributable to potentially modifiable risk factors. Population attributable fractions ranged from $4.9 \%$ for low dietary calcium to $5.4 \%$ for red meat, $8.2 \%$ for processed meat, and $10.3 \%$ for low dietary fiber. ${ }^{61}$ Higher PAFs were observed in men than women. ${ }^{61}$ The PAFs for physical inactivity, excess body weight, alcohol use, and cigarette smoking for men and women combined were $16.3 \%$ (colon cancer only), 5.2\%, 12.8\%, and $11.7 \%$, respectively. ${ }^{61}$

A limitation of studies that estimate PAF caused by exposure is that the effect of all established risk factors cannot be quantified, thereby potentially underestimating the overall proportion attributable. Furthermore, the selected relative risks may differ across age groups. Nonetheless, the data highlight the importance of population education, modification of lifestyle, and implementation of preventive strategies.

\section{Oncological Outcomes}

Survival data for EOCRC are limited and conflicting. Several studies report a worse prognosis, while others demonstrate equivalent or superior outcomes among younger patients. ${ }^{19,20,62,63}$ Younger pa- 
tients typically present with more advanced disease stage and worse pathological features, yet display better or equivalent short-term and long-term survival.

Early age at disease onset is not considered in current therapeutic algorithms for localized or metastatic CRC. Despite being more likely to receive neoadjuvant chemoradiotherapy and adjuvant chemotherapy, younger patients appear to have comparable diseasespecific outcomes with their older counterparts. ${ }^{21,62}$

Why increased access to treatment may not translate into improved disease-specific outcomes is unclear. Unique tumor biology and molecular profiles in younger patients may influence response to treatment. Because of the historically small proportion of patients younger than 50 years, the oncotherapeutic sensitivity of EOCRC is not known in isolation. Conventional chemotherapeutic agents for example appear to confer minimal survival gain in the adjuvant setting. ${ }^{21}$ Younger patients are more likely to receive neoadjuvant and adjuvant therapy outside of current guidelines (stages 1 and 2) but experienced only minimal gain in adjusted survival compared with older counterparts who received less treatment. ${ }^{20,21,62,63} \mathrm{~A}$ nationwide US study of the National Cancer Database found that adjuvant chemotherapy was administered to 826 of 1636 younger patients (50.5\%) vs 923 of 4822 older patients (19.1\%) with low-risk, stage 2 disease. ${ }^{21}$ Furthermore, younger patients were more likely to receive multiagent regimens rather than single-agent therapy. The potential overtreatment of patients with low-risk disease must be questioned in the absence of a definitive oncological benefit.

Modern oncotherapeutic strategies focus on modifying immune system antitumor responses, with striking success observed in microsatellite unstable CRC. ${ }^{64}$ Patients aged younger than 50 years, however, accounted for only a small percentage of the overall study population. It could be postulated that because immune function declines with age, ${ }^{65}$ a more robust peritumoral immune response may occur in individuals with EOCRC compared with their older counterparts, potentially resulting in increased sensitivity to immunotherapy.

\section{Screening}

Current population-based screening strategies require refinement as the epidemiology of CRC changes. In view of the increasing incidence, the American Cancer Society recommended lowering the age of initial screening from 50 to 45 years. A microsimulation analysis screening model was used to evaluate life-years gained, the number of colonoscopies, and the ratios of incremental burden to benefit for different screening strategies. ${ }^{66}$ Notably, recent epidemiological data have shown that the greatest change in incidence is among adults aged 20 to 39 years. Risk stratification on the basis of exposomal factors and family history will be key to defining the optimal screening strategy. The challenge for many countries will be to determine how best to rationalize investigations to screen young individuals who are asymptomatic. Future strategies may include one-time fecal immunohistochemistry testing. Because the event rate of screening colonoscopies would be so low, universal moleculardriven testing may represent an alternative and capture a proportion of patients.
Box. Summary

- The incidence of EOCRC is rising globally. Within the next decade, it is estimated that 1 in 10 colon cancers and 1 in 4 rectal cancers will be diagnosed in adults younger than 50 years.

- The reasons for this increase in incidence are unclear. Potential risk factors include a Westernized diet, obesity, antibiotics, and alterations in the gut microbiome.

- The clinicopathological landscape of EOCRC differs from that of late-onset disease. Younger patients tend to present with advanced disease stage and unfavorable histopathological features. The distal colon and rectum are the most common anatomical sites affected.

- Although genetic predisposition plays a role in EOCRC, most cases are sporadic. To our knowledge, the full spectrum of germline and somatic sequence variations implicated are unknown.

- Survival data are limited and conflicting. Despite accessing more neoadjuvant and adjuvant therapy, patients with EOCRC appear to have oncological outcomes equivalent to those of older counterparts.

Abbreviation: EOCRC, early-onset colorectal cancer.

\section{Discussion}

Early-onset CRC poses many challenges. The underlying molecular profile and drivers of disease remain incompletely understood. Although some sequence variation differences have been observed between early-onset and late-onset disease, unique molecular or gene expression signatures to guide personalized treatment have not yet been identified. The potential of the immune system as a therapeutic target is unknown. Diagnosis has significant consequences for patients and their family members, and consideration must be given to both the oncological and functional implications of treatment. Achieving the balance between reducing cancer risk while preserving bowel and sexual functions and fertility is imperative. Therapeutic algorithms tailored to the biomolecular signature of the tumor are needed to achieve disease control, avoid the morbidity of futile treatments, and enhance quality of life and survivorship.

\section{Limitations}

A limitation of this review is that data on the subject are lacking and predominantly retrospective, with varying cutoff ages used. This hampers interpretation.

\section{Conclusions}

Prospective clinical and scientific studies and trials will decipher the causative mechanisms, molecular typing, and genetic profiles of EOCRC. This will help standardize age-specific preventive, screening, diagnostic, and therapeutic strategies (Box).

\section{ARTICLE INFORMATION}

Accepted for Publication: March 13, 2021.
Published Online: June 30, 2021. doi:10.1001/jamasurg.2021.2380
Correction: This article was corrected on August 11, 2021, to fix an error in the byline. 
The REACCT Collaborative Authors: Alexandra M. Zaborowski, MD; Ahmed Abdile, MD; Michel Adamina, MD; Felix Aigner, MD; Laura d'Allens, MD Caterina Allmer, MD; Andrea Álvarez, MD; Rocio Anula, MD; Mihailo Andric, MD; Sam Atallah, MD; Simon Bach, MD; Miklosh Bala, MD; Marie Barussaud, MD; Augustinas Bausys, MD; Brendan Bebington, MD; Andrew Beggs, MD; Felipe Bellolio, MD; Melissa-Rose Bennett, MD; Anton Berdinskikh MD: Vicki Bevan, MD: Sebastiano Biondo, MD: Gabriele Bislenghi, MD; Marc Bludau, MD; Adam Boutall, MD; Nelleke Brouwer, MD; Carl Brown, MD; Christiane Bruns, MD; Daniel D. Buchanan, PhD Pamela Buchwald, MD; Jacobus W. A. Burger, MD; Nikita Burlov, MD; Michela Campanelli, MD; Maylis Capdepont, MD; Michele Carvello, MD; Hwee-Hoon Chew, MPH; Dimitri Christoforidis, MD; David Clark MD; Marta Climent, MD; Kyle G. Cologne, MD; Tomas Contreras, MD; Roland Croner, MD; Ian R. Daniels, MD; Giovanni Dapri, MD; Justin Davies, MChir; Paolo Delrio, MD; Quentin Denost, MD; Michael Deutsch, MD; Andre Dias, MD; André D'Hoore, MD, PhD; Evgeniy Drozdov, MD; Daniel Duek, MD; Malcolm Dunlop, MD; Adam Dziki, MD Aleksandra Edmundson, PhD; Sergey Efetov, MD Alaa El-Hussuna, MD, PhD; Brodie Elliot, MD Sameh Emile, MD; Eloy Espin, MD; Martyn Evans MD; Seraina Faes, MD; Omar Faiz, MD; Ferga Fleming, MD; Caterina Foppa, MD, PhD; George Fowler, MD; Matteo Frasson, MD; Nuno Figueiredo, MD; Tim Forgan, MD; Frank Frizelle, MbChB; Shamil Gadaev, MD; Jose Gellona, MD; Tamara Glyn, MD; Jianping Gong, MD; Barisic Goran, MD; Emma Greenwood, MD; Marianne G. Guren, MD; Stephanie Guillon, MD; Ida Gutlic, MD; Dieter Hahnloser, MD; Heather Hampel, MD; Ann Hanly, MD; Hirotoshi Hasegawa, MD; Lene Hjerrild Iversen, MD; Andrew Hill, MD; James Hill, MD; Jiri Hoch, MD; Michael Hoffmeister, MD; Roel Hompes, MD Luis Hurtado, MD; Fabiano laquinandi, MD; Ugne Imbrasaite, MD; Rumana Islam, MD; Mehrenah Dorna Jafari, MD; Yukihide Kanemitsu, MD; Aleksei Karachun, MD; Ahmer A. Karimuddin, MD; Deborah S. Keller, MD; Justin Kelly, MD; Rory Kennelly, MD; Gleb Khrykov, MD; Peter Kocian, MD, PhD; Cherry Koh, MD; Neils Kok, MD; Katrina A. Knight, MD Joep Knol, MD; Christos Kontovounisios, MD Hartwig Korner, MD; Zoran Krivokapic, MD; Irmgard Kronberger, MD; Hidde Maarten Kroon, MD; Marius Kryzauskas, MD; Said Kural, MD; Miranda Kusters, MD; Zaher Lakkis, MD; Timur Lankov, MD; Dave Larson, MD, MBA; György Lázár, MD; Kai-Yin Lee, MBBS, MMed; Suk Hwan Lee, MD; Jérémie H. Lefèvre, MD; Anna Lepisto, MD; Christopher Lieu, MD; Lynette Loi, MBChB; Craig Lynch, MD; Helene Maillou-Martinaud, MD; Annalisa Maroli, PhD; Sean Martin, MD; Anna Martling, MD; Klaus E. Matzel, MD; Julio Mayol, MD; Frank McDermott, MD Guillaume Meurette, MD; Monica Millan, MD Martin Mitteregger, MD; Andrei Moiseenko, MD; John R. T. Monson, MD; Stefan Morarasu, MD; Konosuke Moritani, MD; Gabriela Möslein, MD Martino Munini, MD; Caio Nahas, MD; Sergio Nahas MD; Ionut Negoi, MD; Anastasia Novikova, MD Misael Ocares, MD; Koji Okabayashi, MD; Alexandra Olkina, MD; Luis Oñate-Ocaña, MD; Jaime Otero, MD; Cihan Ozen, MD; Ugo Pace, MD; Guilherme Pagin São Julião, MD; Lidiia Panaiotti, MD; Yves Panis, MD; Demetris Papamichael, MD; Jason Park, MD; Swati Patel, MD; Juan Carlos Patrón Uriburu, MD; Miguel Pera, MD; Rodrigo O. Perez, MD; Alexe Petrov, MD; Frank Pfeffer, MD; P. Terry Phang, MD; Tomas Poskus, MD; Heather Pringle, MD; David
Proud, MD; Ivana Raguz, MD; Nuno Rama, MD Shahnawaz Rasheed, MD; Manoj J. Raval, MD; Daniela Rega, MD; Christoph Reissfelder, MD; Juan Carlos Reyes Meneses, MD; Frederic Ris, MD; Stefan Riss, MD; Homero Rodriguez-Zentner, MD; Campbell S. Roxburgh, PhD; Avanish Saklani, MD; Andrea Jiménez Salido, MD; Tarik Sammour, MD Deborah Saraste, MD; Martin Schneider, MD; Ryo Seishima, MD; Aleksandar Sekulic, MD; Toni Seppala, MD; Kieran Sheahan, MD; Rebecca Shine MD; Alexandra Shlomina, MD; Guiseppe S. Sica, MD; Tongplaew Singnomklao, MD; Leandro Siragusa, MD; Neil Smart, MD; Alejandro Solis, MD Antonino Spinelli, MD, PhD; Roxane D. Staiger, MD Michael J. Stamos, MD; Scott Steele, MD; Michael Sunderland, MD; Ker-Kan Tan, MBBS, MMed, PhD; Pieter J. Tanis, MD; Paris Tekkis, MD; Biniam Teklay MD; Sabrina Tengku, MD; Marta Jiménez-Toscano MD; Petr Tsarkov, MD; Matthias Turina, MD; Alexis Ulrich, MD; Bruna B. Vailati, MD; Meike van Harten, MD; Cornelis Verhoef, MD; Satish Warrier, MD; Steve Wexner, MD; Hans de Wilt, MD; Benjamin A. Weinberg, MD; Cameron Wells, MD; Albert Wolthuis, MD; Evangelos Xynos, MD; Nancy You, MD; Alexander Zakharenko, MD; Justino Zeballos, MD: Des C. Winter, MD.

\section{Affiliations of The REACCT Collaborative}

Authors: Centre for Colorectal Disease, St Vincent's University Hospital, Dublin, Ireland (Zaborowski، Hanly, Kennelly, Martin, Morarasu, Sheahan, Winter); Department of Surgery, Middlemore Hospital, Auckland, New Zealand (Abdile, A. Hill); Department of Surgery, Cantonal Hospital, Winterthur, Switzerland (Adamina, d'Allens) Department of Surgery, Barmherzige Brüde Krankenhaus Graz, Graz, Austria (Aigner, Allmer, Mitteregger); Department of Surgery, Bellvitge University Hospital, Barcelona, Spain (Álvarez, Biondo, Climent); Department of Surgery, Instituto de Investigación Sanitaria San Carlos, Universidad Complutense de Madrid, Hospital Clínico San Carlos, Madrid, Spain (Anula, Mayol, Otero) Department of Surgery, University Hospital Magdeburg, Magdeburg, Germany (Andric, Croner) Department of Colorectal Surgery, AdventHealth, Orlando, Florida (Atallah); Department of Surgery, Queen Elizabeth Hospital, Birmingham, United Kingdom (Bach, Beggs); Department of Surgery, Hadassah-Hebrew University Medical Center, Jerusalem, Israel (Bala); Department of Surgery, University Hospital Poitiers, Poitiers, France (Barussaud); Department of Surgery, National Cancer Institute, Vilnius, Lithuania (Bausys); Department of Surgery, Wits Donald Gordon Medical Centre, Johannesburg, South Africa (Bebington); Department of Digestive Surgery, Faculty of Medicine, Pontificia Universidad Catolic de Chile, Santiago, Chile (Bellolio); Department of Surgery, Royal Devon and Exeter Hospital, Exeter, United Kingdom (Bennett, Daniels, Fowler, McDermott, Pringle, Smart); Department of Surgery, St-Petersburg Clinical Scientific and Practical Centre, St Petersburg, Russia (Berdinskikh); Department of Surgery, Morriston Hospital, Swansea, Wales, United Kingdom (Bevan, Evans); Department of Surgery, UZ Leuven, Leuven, Belgium (Bislenghi, D'Hoore, Wolthuis): Department of Surgery, University Hospital Cologne, Cologne, Germany (Bludau, Bruns); Department of Surgery, Groote Schuur Hospital, University of Cape Town, Cape Town, South Africa (Boutall); Department of Surgery, Radboud University Medical Center, Nijmegen, The
Netherlands (Brouwer, de Wilt); Department of Surgery, St Paul's Hospital, the University of British Columbia, Vancouver, British Columbia, Canada (Brown); Department of Clinical Pathology, the University of Melbourne, Victorian Comprehensive Cancer Centre, Melbourne, Australia (Buchanan); Department of Surgery, Skåne University Hospital, Malmö, Sweden (Buchwald, Gutlic); Department of Surgery, Catharina Hospital, Eindhoven,

The Netherlands (Burger); Department of Surgery, Leningrad Regional Clinical Oncology Dispensary, Leningrad, Russia (Burlov, Khrykov); Department of Surgery, Policlinico Tor Vergata, Rome, Italy (Campanelli, Sica, Siragusa); Department of Surgery, Bordeaux University Hospital, Bordeaux France (Capdepont, Denost, Guillon, Maillou-Martinaud); Division of Colon and Rectal Surgery, IRCCS Humanitas Research Hospital, Rozzano, Milan, Italy (Carvello, Foppa, Maroli); Division of Colorectal Surgery, University Surgical Cluster, National University Health System, Singapore, Singapore (Chew, K. Lee); Department of Surgery, Lugano Regional Hospital, Lugano, Switzerland (Christoforidis, laquinandi, Munini); Department of Surgery, Royal Brisbane and Women's Hospital, Brisbane, Queensland, Australia (Clark, Edmundson); Department of Surgery, Keck Hospital, University of Southern California, Los Angeles (Cologne); Department of Surgery, Pontificia Universidad Catolica de Chile, Santiago, Chile (Contreras); Department of Surgery, St-Pierre University Hospital, Brussels, Belgium (Dapri); Cambridge Colorectal Unit, Addenbrooke's Hospital, Cambridge, United Kingdom (Davies); Colorectal Surgical Oncology, Abdominal Oncology Department, Istituto Nazionale per lo Studio e la Cura dei Tumori, "Fondazione G. Pascale" IRCSS, Naples, Italy (Delrio, Pace, Rega); Department of Surgery, Milton S. Hershey Medical Center, Hershey, Pennsylvania (Deutsch); Department of Surgery, Institute of Cancer of São Paulo, São Paulo, Brazil (Dias, C. Nahas, S. Nahas); Department of Surgery, Siberian State Medical University, Tomsk, Russia (Drozdov); Department of Surgery, Rambam Health Care Campus, Haifa, Israel (Duek); Department of Surgery, Western General Hospital, Edinburgh, United Kingdom (Dunlop); Department of Surgery, Military Medical Academy University Teaching Hospital, Łódź, Poland (Dziki); Department of Surgery, Sechenov First Moscow State Medical University, Moscow, Russia (Efetov, Shlomina, Tsarkov); Department of Surgery, Aalborg University Hospital, Aalborg, Denmark (El-Hussuna, Ozen); Department of Surgery, Whangarei Hospital Whangarei, New Zealand (Elliot, Sunderland); Department of Surgery, Mansoura University Hospital, Mansoura, Egypt (Emile); Colorectal Surgery Unit, General Surgery Service, Hospital Vall de Hebron, Barcelona, Spain (Espin, Solis); Department of Visceral Surgery, University Hospital Lausanne, Lausanne, Switzerland (Faes, Hahnloser); Department of Surgery, St Mark's Hospital, London, United Kingdom (Faiz); Department of Surgery, University of Rochester, New York (Fleming); Department of Surgery, University Hospital La Fe, Valencia, Spain (Frasson, Hurtado); Department of Surgery, Champalimaud Clinical Centre, Lisbon, Portugal (Figueiredo) Department of Surgery, Tygerberg Academic Hospital, Cape Town, South Africa (Forgan); Department of Surgery, Christchurch Hospital, Christchurch, New Zealand (Frizelle); Fourth Coloproctology Department, St Petersburg 
Oncology Center, St Petersburg, Russia (Gadaev); Department of Colorectal Surgery, Clínica Santa María, Santiago, Chile (Gellona); Department of Colorectal Surgery, Hospital Militar de Santiago, Le Reina, Chile (Gellona); Department of Surgery, Christchurch Hospital, Christchurch, New Zealand (Glyn); Department of Surgery, Tongji Hospital, Wuhan, China (Gong); Department of Surgery, Clinical Center of Serbia, Belgrade, Serbia (Goran, Krivokapic, Sekulic); Department of Surgery, Royal Adelaide Hospital, Adelaide, South Australia, Australia (Greenwood, van Harten); Department of Oncology, Oslo University Hospital, Oslo, Norway (Guren); Division of Human Genetics, The Ohio State University Comprehensive Cancer Center, Columbus (Hampel); Department of Surgery, Tokyo Dental College Ichikawa General Hospital, Chiba, Japan (Hasegawa); Department of Surgery, Aarhus University Hospital, Aarhus, Denmark (Iversen): Department of Surgery, Manchester Royal Infirmary, Manchester, United Kingdom (J. Hill); Department of Surgery, Motol University Hospital, Prague, Czech Republic (Hoch); Department of Surgery, German Cancer Research Center, Heidelberg, Germany (Hoffmeister); Department of Surgery, Amsterdam University Medical Center, Amsterdam, The Netherlands (Hompes); Vilnius University, Faculty of Medicine, Vilnius, Lithuania (Imbrasaite, Kryzauskas); Department of Surgery, Austin Hospital, Melbourne, Australia (Islam, Proud, Shine); School of Medicine, University of California Irvine, Irvine (Jafari, Stamos); Department of Colorectal Surgery, National Cancer Center Hospital, Tokyo, Japan (Kanemitsu, Moritani); Surgical Department of Abdominal Oncology, N. N. Petrov National Medical Research Centre of Oncology, St Petersburg, Russia (Karachun, Lankov, Moiseenko, Olkina, Panaiotti, Petrov); Department of Surgery, St Paul's Hospital, Vancouver, British Columbia, Canada (Karimuddin, Phang, Raval); Division of Colorectal Surgery, Department of Surgery, University of California at Davis Medical Center, Sacramento (Keller); Advent Health Colorectal Surgery, Orlando, Florida (Kelly) Department of Surgery, Motol University Hospital, Prague, Czech Republic (Kocian); Department of Surgery, Royal Prince Alfred Hospital, Sydney, Australia (Koh); Department of Surgery, The Netherlands Cancer Institute, Amsterdam, The Netherlands (Kok); University of Glasgow, Glasgow, United Kingdom (Knight, Loi, Tengku); Department of Surgery, Ziekenhuis Oost-Limburg Belgium (Knol); Department of Surgery, Royal Marsden Hospital, London, United Kingdom (Kontovounisios, Rasheed, Tekkis); Department of Surgery, Stavanger University Hospital, Stavanger, Norway (Korner); Medical University Innsbruck, Innsbruck, Austria (Kronberger); Department of Surgery, University of Adelaide, Royal Adelaide Hospital, Adelaide, Australia (Kroon, Sammour); School of Medicine, Uludag University, Bursa, Turkey (Kural); Department of Surgery, Amsterdam University Medical Centers, location VUmc, Amsterdam, The Netherlands (Kusters): Department of Surgery, University Hospital Besançon, Besançon, France (Lakkis); Department of Surgery, Mayo Clinic, Rochester, Minnesota (Larson); Department of Surgery, University of Szeged, Szeged, Hungary (Lázár); Kyung Here University Hospital at Gangdong, Seoul, South Korea (S. H. Lee); Sorbonne Université, Department of Digestive Surgery, Assistance Publique-Hôpitaux de Paris, Hôpital St Antoine, Paris, France (Lefèvre);
Department of Surgery, Helsinki University Hospital, Helsinki, Finland (Lepisto, Seppala); Division of Medical Oncology, University of Colorado Anschutz Medical Campus, Aurora (Lieu): Department of Surgery, St Vincent's Hospital, University of Melbourne, Melbourne, Australia (Lynch); Department of Surgery, Karolinska University Hospital, Stockholm, Sweden (Martling, Singnomklao); Department of Surgery, University Hospital Erlangen, Erlangen, Germany (Matzel); Department of Surgery, University Hospital Nantes, Nantes, France (Meurette); Department of Surgery, La Fe University Hospital, Valencia, Spain (Millan); AdventHealth Medical Group Colorectal Surgery, AdventHealth, Orlando, Florida (Monson); Department for Hereditary Tumors, Evangelisches Krankenhaus Bethesda, Duisburg, Germany (Möslein); Department of Surgery, Emergency Hospital of Bucharest, Bucharest, Romania (Negoi); Department of Surgery, Pavlov First St Petersburg State Medical University's Clinic, St Petersburg, Russia (Novikova, Zakharenko); Department of Surgery, University Hospital Concepción, Concepción, Chile (Ocares); Department of Surgery, Keio University, Tokyo, Japan (Okabayashi, Seishima); Department of Surgery, National Cancer Institute, Mexico City, Mexico (Oñate-Ocaña) Department of Surgery, Angelita and Joaquim Gama Institute, São Paulo, Brazil (São Julião, Vailati); Department of Surgery, Beaujon Hospital, Paris, France (Panis); Department of Medical Oncology, Bank of Cyprus Oncology Centre, Nicosia, Cyprus (Papamichael); Department of Surgery, St Boniface General Hospital, Winnipeg, Manitoba, Canada (Park); Department of Gastroenterology, University of Colorado Anschutz Medical Campus, Aurora (Patel); Colorectal Surgery Department, British Hospital of Buenos Aires, Buenos Aires, Argentina (Patrón Uriburu); Department of Surgery, Hospital del Mar, Barcelona, Spain (Pera, Salido, Jiménez-Toscano); Colorectal Surgery Division, Angelita and Joaquim Gama Institute, Hospital Alemão Oswaldo Cruz, São Paulo, Brazil (Perez); Department of Surgery, Haukeland University Hospital, Bergen, Norway (Pfeffer); Faculty of Medicine, Vilnius University, Vilnius, Lithuania (Poskus); Department of Surgery, University Hospital Zurich, Zurich, Switzerland (Raguz, Staiger, Turina); Department of Surgery, Centro Hospitalar de Leiria, Leiria, Portugal (Rama); Department of Surgery, Mannheim University Hospital, Mannheim, Germany (Reissfelder); Department of Surgery, Colombia National University Hospital, Bogota, Columbia (Reyes Meneses); Department of Surgery, University Hospital Geneva, Geneva, Switzerland (Ris); Department of Surgery, Medical University Vienna, Vienna, Austria (Riss); Department of Surgery, Hospital Punta Pacífica, Panama City, Panama (Rodriguez-Zentner); Glasgow Royal Infirmary, Institute of Cancer Sciences, University of Glasgow, Glasgow, United Kingdom (Roxburgh); Department of Surgery, Tata Memorial Centre, Mumbai, India (Saklani); Department of Surgery, Stockholm South General Hospital, Stockholm, Sweden (Saraste); Department of Surgery, Heidelberg University Hospital, Heidelberg, Germany (Schneider); Department of Biomedical Sciences, Humanitas University, Division of Colon and Rectal Surgery, IRCCS Humanitas Research Hospital, Rozzano, Milan, Italy (Spinelli); Department of Surgery, Cleveland Clinic, Cleveland, Ohio (Steele); Department of Surgery, School of Medicine,
National University of Singapore, Singapore, Singapore (Tan); Department of Surgery, Amsterdam University Medical Centers, University of Amsterdam, Cancer Centre Amsterdam, Amsterdam, The Netherlands (Tanis); Department of Surgery, Åbenrå Hospital, Åbenrå, Denmark (Teklay); Department of Surgery, Lukas Hospital, Neuss, Germany (Ulrich); Department of Surgery. Erasmus University Medical Centre, Rotterdam, The Netherlands (Verhoef); Department of Surgery, Peter MacCallum Cancer Centre, Melbourne, Australia (Warrier); Department of Surgery, Cleveland Clinic Florida, Weston (Wexner); Lombardi Comprehensive Cancer Center, Georgetown University Medical Center, Washington, DC (Weinberg); Department of Surgery, Auckland City Hospital, Auckland, New Zealand (Wells); Department of Surgery, Creta Inter-Clinic Hospital, Heraklion, Crete, Greece (Xynos); Department of Surgery, MD Anderson Cancer Center, Houston, Texas (You); Department of Surgery, Maciel Hospital, Montevideo, Uruguay (Zeballos).

Author Contributions: Drs Zaborowski and Winter had full access to all of the data in the study and take responsibility for the integrity of the data and the accuracy of the data analysis.

Concept and design: Zaborowski, Bebington, Beggs, Berdinskikh, Bislenghi, Buchwald, Climent, D'Hoore, Dunlop, Faes, Faiz, Fleming, Frizelle, Gong Hampel, J. Hill, Hoch, Imbrasaite, Keller, Kennelly, Khrykov, Kocián, Knol, Kryzauskas, Larson, Lepistö, Lieu, Martling, Mayol, Monson, C. Nahas, S. Nahas, Negoi, Ocares, Oñate-Ocaña, Panis, Papamichael, Park, Phang, Rasheed, Riss, Schneider, Seppälä, Teklay, Tsarkov, Turina, Warrier, Wexner, Wolthuis, Xynos, You, Winter.

Acquisition, analysis, or interpretation of data: Zaborowski, Abdile, Adamina, Aigner, d'Allens, Allmer, Álvarez, Anula, Andric, Atallah, Bach, Bala, Barussaud, Bausys, Bebington, Bellolio, Bennett, Bevan, Biondo, Bludau, Boutall, Brouwer, Brown, Bruns, Buchanan, Burger, Burlov, Campanelli, Capdepont, Carvello, Chew, Christoforidis, Clark, Cologne, Contreras, Croner, Daniels, Dapri, Davies, Delrio, Denost, Deutsch, Dias, D'Hoore, Drozdov, Duek, Dziki, Edmundson, Efetov, El-Hussuna, Elliott, Emile, Espin-Basany, Evans, Faes, Foppa, Fowler, Frasson, Figueiredo, Forgan, Gadaev, Gellona, Glyn, Gong, Goran, Greenwood, Guren, Guillon, Gutlic, Hahnloser, Hanly, Hasegawa, Hjerrild Iversen, A. Hill, Hoffmeister, Hompes, Hurtado-Pardo, Iaquinandi, Islam, Jafari, Kanemitsu, Karachun, Karimuddin, Keller, Kelly, Khrykov, Koh, Kok, Knight, Kontovounisios, Kørner, Krivokapic, Kronberger, Kroon, Kural, Kusters, Lakkis, Lankov, Larson, Lázár, K. Lee, S. Lee, Lefèvre, Lieu, Loi, Lynch, Maillou-Martinaud, Maroli, Martin, Martling, Matzel, Mayol, McDermott, Meurette, Millan, Mitteregger, Moiseenko, Monson, Morarasu, Moritani, Moeslein, Munini, Negoi, Novikova, Okabayashi, Olkina, Otero de Pablos Ozen, Pace, São Julião, Panaiotti, Patel, Patrón Uriburu, Pera, Perez, Petrov, Pfeffer, Poskus, Pringle, Proud, Raguz, Rama, Raval, Rega, Reissfelder, Reyes-Meneses, Ris, Rodriguez-Zentner, Roxburgh, Saklani, Jiménez Salido, Sammour, Saraste, Seishima, Sekulic, Seppälä, Sheahan, Shine, Shlomina, Sica, Singnomklao, Siragusa, Smart, Solis-Peña, Spinelli, Staiger, Stamos, Steele, Sunderland, Tan, Tanis, Tekkis, Tengku, Jiménez Toscano, Ulrich, Vailati, van Harten, Verhoef, de Wilt, Weinberg, Wells, You, 
Zakharenko, Zeballos.

Drafting of the manuscript: Zaborowski, Abdile, Adamina, Atallah, Bevan, Buchwald, Burger, Campanelli, D'Hoore, Drozdov, Elliott, Forgan, Frizelle, Gong, laquinandi, Karachun, Keller, Kennelly, Knight, Knol, Kontovounisios, Larson, K. Lee, Lieu, Moiseenko, Moritani, Munini, Novikova, Ocares, Oñate-Ocaña, Otero de Pablos, Ozen, Panaiotti, Papamichael, Pfeffer, Rega, Ris, Riss, Jiménez Salido, Seishima, Siragusa, Solis-Peña, Tekkis, Xynos, Zakharenko, Winter. Critical revision of the manuscript for important intellectual content: Zaborowski, Adamina, Aigner d'Allens, Allmer, Álvarez, Anula, Andric, Bach, Bala, Barussaud, Bausys, Bebington, Beggs, Bellolio, Bennett, Berdinskikh, Biondo, Bislenghi, Bludau, Boutall, Brouwer, Brown, Bruns, Buchanan, Buchwald, Burlov, Capdepont, Carvello, Chew, Christoforidis, Clark, Climent, Cologne, Contreras, Croner, Daniels, Dapri, Davies, Delrio, Denost Deutsch, Dias, D'Hoore, Duek, Dunlop, Dziki, Edmundson, Efetov, El-Hussuna, Emile, Espin-Basany, Evans, Faes, Faiz, Fleming, Foppa, Fowler, Frasson, Figueiredo, Frizelle, Gadaev، Gellona, Glyn, Gong, Goran, Greenwood, Guren, Guillon, Gutlic, Hahnloser, Hampel, Hanly, Hasegawa, Hjerrild Iversen, A. Hill, J. Hill, Hoch, Hoffmeister, Hompes, Hurtado-Pardo, Imbrasaite Islam, Jafari, Kanemitsu, Karimuddin, Keller, Kelly, Khrykov, Kocián, Koh, Kok, Kørner, Krivokapic, Kronberger, Kroon, Kryzauskas, Kural, Kusters, Lakkis, Lankov, Larson, Lázár, S. Lee, Lefèvre, Lepistö, Lieu, Loi, Lynch, Maillou-Martinaud, Maroli, Martin, Martling, Matzel, Mayol, McDermott, Meurette, Millan, Mitteregger, Monson, Morarasu, Moeslein, C. Nahas, S. Nahas, Negoi, Okabayashi, Olkina, Ozen, Pace, São Julião, Panis, Park, Patel, Patrón Uriburu, Pera, Perez, Petrov, Phang, Poskus, Pringle, Proud, Raguz, Rama, Rasheed, Raval, Reissfelder, Reyes-Meneses, Ris, Rodriguez-Zentner, Roxburgh, Saklani, Sammour, Saraste, Schneider, Sekulic, Seppälä, Sheahan, Shine, Shlomina, Sica, Singnomklao, Smart, Spinelli, Staiger, Stamos, Steele, Sunderland, Tan, Tanis, Teklay, Tengku, Jiménez Toscano, Tsarkov, Turina, Ulrich, Vailati, van Harten, Verhoef, Warrier, Wexner, de Wilt, Weinberg, Wells, Wolthuis, You, Zeballos.

Statistical analysis: Berdinskikh, Espin-Basany, Moiseenko, Morarasu, Park, Poskus, Pringle, Raguz, Tan, You.

Obtained funding: Álvarez, Efetov, Figueiredo, Khrykov, Moritani, Ocares.

Administrative, technical, or material support: Zaborowski, Abdile, Aigner, Atallah, Barussaud Bausys, Bruns, Buchanan, Chew, Croner, Dapri, Davies, Dias, D'Hoore, Drozdov, Dunlop، Edmundson, Elliott, Espin-Basany, Evans, Faes, Forgan, Frizelle, Glyn, Goran, Greenwood, Hoffmeister, Kanemitsu, Karimuddin, Keller, Kelly, Khrykov, Kok, Knight, Knol, Krivokapic, Kroon, Kural, Lankov, Lázár, K. Lee, Lieu, Matzel, McDermott, Moritani, Ocares, Otero de Pablos, Papamichael, Pringle, Proud, Raguz, Rasheed, Rega, Reissfelder, Roxburgh, Sammour, Schneider, Seppälä, Sheahan, Sica, Singnomklao, Siragusa, Smart, Tan, Tanis, Tekkis, Teklay, Vailati, van Harten Warrier, You, Zeballos.

Supervision: Adamina, Bach, Beggs, Buchwald, Campanelli, Carvello, Climent, Cologne, Delrio, D'Hoore, Dziki, El-Hussuna, Emile, Espin-Basany, Faes, Faiz, Figueiredo, Frizelle, Gong, Hahnloser, Hjerrild Iversen, A. Hill, Hoch, Hurtado-Pardo,
Imbrasaite, Jafari, Keller, Kennelly, Khrykov, Kocián, Koh, Kroon, Kryzauskas, Larson, Lieu, Martin, Martling, McDermott, Monson, Moeslein, C. Nahas, S. Nahas, Negoi, Okabayashi, São Julião, Panis, Patel, Perez, Poskus, Ris, Riss, Roxburgh, Sammour, Steele, Tsarkov, Turina, van Harten, Warrier, Wexner, de Wilt, Wolthuis, You, Winter Other-acquisition of data: Gadaev, Munini. Other: Bislenghi, Bludau, Gutlic, Shlomina, Spinelli. Other-data collection and in-house analysis: Deutsch.

\section{Conflict of Interest Disclosures: Dr Bebington} reported grants from Medical Research Council South Africa as part of a Medical Research Council CURE grant and personal fees from Wits Consortium Salary as a past head of colorectal surgery during the conduct of the study; also, as a researcher in the developing world, Dr Bebington is constantly seeking opportunities to collaborate with institutions such as the Sloan Kettering, which has not unduly affected the honesty of data provided for the research nor the contribution he has made to intellectual content but could be construed as such. Dr Bruns reported personal fees from Medtronic as an advisory board member and Promedicis for Excellence in Oncology and grants from Intuitive for the ESOMAP trial and SIRTex for the ESSURE registry outside the submitted work. Dr Daniels reported personal fees from Origin Sciences, where he is a chief medical officer, appointed in August 2020; personal fees from Medtronic/Covidien and BD/Bard for teaching and advising; and nonfinancial support from Colostomy UK as honorary president of a charity focused on support for people with stomas, outside the submitted work. Dr Dunlop reported grants from University of Edinburgh during the conduct of the study. Dr Fleming reported author royalties from UptoDate outside the submitted work. Dr Frasson reported personal fees from J\&J Consultory outside the submitted work. Dr Figueiredo reported personal fees for consulting and lectures from Johnson \& Johnson outside the submitted work. Dr Frizelle reported serving as the editor of another Journal. Dr Hampel reported advisory board membership with Invitae Scientific, Genome Medical Scientific, and Promega Scientific outside the submitted work. Dr Karimuddin reported speaker's fees from Servier outside the submitted work. Dr Lynch reported proctoring fees from Device Technologies and honoraria from Stryker outside the submitted work. Dr Mayol reported personal fees from Novartis, Boehringer Ingelheim Astellas, Rovi, SOBI, Shionogi, Alcon, Roche, and Johnson \& Johnson outside the submitted work. Dr São Julião reported personal fees from Johnson and Johnson, Roche, and Merck Sharp \& Dohme outside the submitted work. Dr Pfeffer reported a research grant from Intuitive Surgical outside the submitted work. Dr Ris reported personal fees from Arthrex, Distal Motion, and Stryker and grants from Quantgene outside the submitted work. Dr Saraste reported grants from Bengt Ihre Foundation and Mag-Tarmfonden during the conduct of the study. Dr Seppälä reported being the CEO and co-owner from Healthfund Finland Ltd and interview honoraria from Boehringer Ingelheim Finland outside the submitted work. Dr Smart reported personal fees (speaker's fees for hernia surgery) from Medtronic and WL Gore outside the submitted work. Dr Spinelli reported personal fees from Ethicon, Takeda, Janssen, Sofar, and Oasis outside the submitted work. Dr Tanis reported grants from LifeCell and Allergan outside the submitted work. Dr Vailati reported personal fees from Medtronic and Johnson \& Johnson outside the submitted work. Dr Wexner reported consulting fees from Intuitive Surgical, Stryker, Medtronic, Tigenix, Axonics, Baxter, LiCor, and AISChannel; stock options from Regentys, LifeBond, Pragma, and Renew Medical; royalties from Medtronic, Intuitive Surgical, Karl Storz Endoscopy America, and Unique Surgical Innovations; and inactive consulting relationships with CRH Medical and Intuitive Surgical. Dr de Wilt reported grants from Dutch Cancer Society, ZonMW (The Netherlands Organisation for Health Research and Development), Bergh in het Zadel Foundation, and Medtronic to his institution outside the submitted work. No other disclosures were reported.

\section{REFERENCES}

1. Jacobs $D$, Zhu R, Luo J, et al. Defining early-onset colon and rectal cancers. Front Oncol. 2018;8:504. doi:10.3389/fonc.2018.00504

2. Vuik FE, Nieuwenburg SA, Bardou M, et al. Increasing incidence of colorectal cancer in young adults in Europe over the last 25 years. Gut. 2019; 68(10):1820-1826. doi:10.1136/gutjnl-2018-317592

3. Chambers AC, Dixon SW, White $P$, Williams AC, Thomas MG, Messenger DE. Demographic trends in the incidence of young-onset colorectal cancer: a population-based study. Br J Surg. 2020;107(5): 595-605. doi:10.1002/bjs.11486

4. Bailey CE, Hu CY, You YN, et al. Increasing disparities in the age-related incidences of colon and rectal cancers in the United States, 1975-2010. JAMA Surg. 2015:150(1):17-22. doi:10.1001/ jamasurg.2014.1756

5. Lui RN, Tsoi KKF, Ho JMW, et al. Global increasing incidence of young-onset colorectal cancer across 5 continents: a joinpoint regression analysis of 1,922,167 cases. Cancer Epidemiol Biomarkers Prev. 2019;28(8):1275-1282. doi:10. 1158/1055-9965.EPI-18-1111

6. Bhandari A, Woodhouse M, Gupta S. Colorectal cancer is a leading cause of cancer incidence and mortality among adults younger than 50 years in the USA: a SEER-based analysis with comparison to other young-onset cancers. J Investig Med. 2017; 65(2):311-315. doi:10.1136/jim-2016-000229

7. Siegel RL, Jemal A, Ward EM. Increase in incidence of colorectal cancer among young men and women in the United States. Cancer Epidemiol Biomarkers Prev. 2009;18(6):1695-1698. doi:10. 1158/1055-9965.EPI-09-0186

8. Crosbie AB, Roche LM, Johnson LM, Pawlish KS Paddock LE, Stroup AM. Trends in colorectal cancer incidence among younger adults-Disparities by age sex, race, ethnicity, and subsite. Cancer Med. 2018; 7 (8):4077-4086. doi:10.1002/cam4.1621

9. Austin H, Henley SJ, King J, Richardson LC, Eheman C. Changes in colorectal cancer incidence rates in young and older adults in the United States: what does it tell us about screening. Cancer Causes Control. 2014;25(2):191-201. doi:10.1007/s10552013-0321-y

10. Willauer AN, Liu Y, Pereira AAL, et al. Clinical and molecular characterization of early-onset colorectal cancer. Cancer. 2019;125(12):2002-2010. doi:10.1002/cncr.31994

11. Meyer JE, Narang T, Schnoll-Sussman FH, Pochapin MB, Christos PJ, Sherr DL. Increasing 
incidence of rectal cancer in patients aged younger than 40 years: an analysis of the surveillance, epidemiology, and end results database. Cancer. 2010;116(18):4354-4359. doi:10.1002/cncr.25432

12. Siegel RL, Miller KD, Fedewa SA, et al. Colorectal cancer statistics, 2017. CA Cancer J Clin. 2017;67(3):177-193. doi:10.3322/caac.21395

13. Saltzstein SL, Behling CA. Age and time as factors in the left-to-right shift of the subsite of colorectal adenocarcinoma: a study of 213,383 cases from the California Cancer Registry. J Clin Gastroenterol. 2007:41(2):173-177. doi:10.1097/01. mcg.0000225550.26751.6a

14. Suttie SA, Shaikh I, Mullen R, Amin Al, Daniel T, Yalamarthi S. Outcome of right- and left-sided colonic and rectal cancer following surgical resection. Colorectal Dis. 2011;13(8):884-889. doi:10.1111/j.1463-1318.2010.02356.x

15. Lim DR, Kuk JK, Kim T, Shin EJ. Comparison of oncological outcomes of right-sided colon cancer versus left-sided colon cancer after curative resection: which side is better outcome? Medicine (Baltimore). 2017;96(42):e8241. doi:10.1097/MD. 0000000000008241

16. Powell AG, Wallace R, McKee RF, et al. The relationship between tumour site, clinicopathological characteristics and cancer-specific survival in patients undergoing surgery for colorectal cancer. Colorectal Dis. 2012;14 (12):1493-1499. doi:10.1111/j.1463-1318.2012.03048.x 17. Liang JT, Huang KC, Cheng $A L$, Jeng YM, Wu MS, Wang SM. Clinicopathological and molecular biological features of colorectal cancer in patients less than 40 years of age. Br J Surg. 2003; 90(2):205-214. doi:10.1002/bjs.4015

18. You YN, Xing Y, Feig BW, Chang GJ, Cormier JN. Young-onset colorectal cancer: is it time to pay attention? Arch Intern Med. 2012;172(3):287-289. doi:10.1001/archinternmed.2011.602

19. O'Connell JB, Maggard MA, Liu JH, Etzioni DA, Livingston EH, Ko CY. Do young colon cancer patients have worse outcomes? World J Surg. 2004;28(6):558-562. doi:10.1007/s00268-0047306-7

20. Saraste $D$, Järås J, Martling A.

Population-based analysis of outcomes with early-age colorectal cancer. Br J Surg. 2020;107(3): 301-309. doi:10.1002/bjs.11333

21. Kneuertz PJ, Chang GJ, Hu CY, et al. Overtreatment of young adults with colon cancer: more intense treatments with unmatched survival gains. JAMA Surg. 2015;150(5):402-409. doi:10. 1001/jamasurg.2014.3572

22. Abdelsattar ZM, Wong SL, Regenbogen SE, Jomaa DM, Hardiman KM, Hendren S. Colorectal cancer outcomes and treatment patterns in patients too young for average-risk screening. Cancer. 2016;122(6):929-934. doi:10.1002/cncr.29716 23. O'Connell JB, Maggard MA, Livingston EH, Yo CK. Colorectal cancer in the young. Am J Surg. 2004;187(3):343-348. doi:10.1016/j.amjsurg.2003. 12.020

24. Dozois EJ, Boardman LA, Suwanthanma W, et al. Young-onset colorectal cancer in patients with no known genetic predisposition: can we increase early recognition and improve outcome? Medicine (Baltimore). 2008;87(5):259-263. doi:10.1097/MD. Ob013e3181881354
25. Connell LC, Mota JM, Braghiroli MI, Hoff PM. The rising incidence of younger patients with colorectal cancer: questions about screening, biology, and treatment. Curr Treat Options Oncol. 2017;18(4):23. doi:10.1007/s11864-017-0463-3

26. Chang DT, Pai RK, Rybicki LA, et al. Clinicopathologic and molecular features of sporadic early-onset colorectal adenocarcinoma: an adenocarcinoma with frequent signet ring cell differentiation, rectal and sigmoid involvement, and adverse morphologic features. Mod Pathol. 2012;25(8):1128-1139. doi:10.1038/modpathol. 2012.61

27. Shin US, Yu CS, Kim JH, et al. Mucinous rectal cancer: effectiveness of preoperative chemoradiotherapy and prognosis. Ann Surg Oncol. 2011;18(8):2232-2239. doi:10.1245/s10434-011-1612-8

28. McCawley N, Clancy C, O'Neill BD, Deasy J, McNamara DA, Burke JP. Mucinous rectal adenocarcinoma is associated with a poor response to neoadjuvant chemoradiotherapy: a systematic review and meta-analysis. Dis Colon Rectum. 2016;59(12): 1200-1208. doi:10.1097/DCR.0000000000000635

29. Antelo M, Balaguer F, Shia J, et al. A high degree of LINE-1 hypomethylation is a unique feature of early-onset colorectal cancer. PLoS One. 2012;7(9):e45357. doi:10.1371/journal.pone.0045357

30. Lieu CH, Golemis EA, Serebriiskii IG, et al. Comprehensive genomic landscapes in early and later onset colorectal cancer. Clin Cancer Res. 2019;25(19): 5852-5858. doi:10.1158/1078-0432.CCR-19-0899

31. Serebriiskii IG, Connelly C, Frampton G, et al. Comprehensive characterization of RAS mutations in colon and rectal cancers in old and young patients. Nat Commun. 2019;10(1):3722. doi:10. 1038/s41467-019-11530-0

32. Eriksson J, Amonkar M, Al-Jassar G, et al. Mismatch repair/microsatellite instability testing practices among US physicians treating patients with advanced/metastatic colorectal cancer. J Clin Med. 2019;8(4):E558. doi:10.3390/jcm8040558

33. Seppälä TT, Latchford A, Negoi I, et al; on behalf of the European Hereditary Tumour Group (EHTG) and European Society of Coloproctology (ESCP). European guidelines from the EHTG and ESCP for Lynch syndrome: an updated third edition of the Mallorca guidelines based on gene and gender. Br J Surg. Published September 21, 2020. doi:10.1002/bjs.11902

34. Kirzin S, Marisa L, Guimbaud R, et al. Sporadic early-onset colorectal cancer is a specific sub-type of cancer: a morphological, molecular and genetics study. PLoS One. 2014;9(8):e103159. doi:10.1371/ journal.pone.0103159

\section{Arriba M, García JL, Rueda D, et al.} Unsupervised analysis of array comparative genomic hybridization data from early-onset colorectal cancer reveals equivalence with molecular classification and phenotypes. Neoplasia. 2017;19(1):28-34. doi:10.1016/j.neo.2016.11.006

36. Guinney J, Dienstmann R, Wang X, et al. The consensus molecular subtypes of colorectal cancer. Nat Med. 2015;21(11):1350-1356. doi:10. 1038/nm.3967

37. Goel A, Nagasaka T, Spiegel J, Meyer R, Lichliter WE, Boland CR. Low frequency of Lynch syndrome among young patients with non-familial colorectal cancer. Clin Gastroenterol Hepatol. 2010; 8(11):966-971. doi:10.1016/j.cgh.2010.06.030
38. Pearlman R, Frankel WL, Swanson B, et al; Ohio Colorectal Cancer Prevention Initiative Study Group. Prevalence and spectrum of germline cancer susceptibility gene mutations among patients with early-onset colorectal cancer. JAMA Oncol. 2017;3 (4):464-471. doi:10.1001/jamaoncol.2016.5194

39. Mork ME, You YN, Ying J, et al. High prevalence of hereditary cancer syndromes in adolescents and young adults with colorectal cancer. J Clin Oncol. 2015;33(31):3544-3549. doi:10.1200/JCO.2015.61.4503

40. Lynch HT, Snyder CL, Shaw TG, Heinen CD, Hitchins MP. Milestones of Lynch syndrome: 1895-2015. Nat Rev Cancer. 2015;15(3):181-194. doi: $10.1038 /$ nrc3878

41. Sehgal R, Sheahan $K$, O'Connell PR, Hanly AM, Martin ST, Winter DC. Lynch syndrome: an updated review. Genes (Basel). 2014;5(3):497-507. doi:10. 3390/genes5030497

42. Stoffel EM, Koeppe E, Everett J, et al. Germline genetic features of young individuals with colorectal cancer. Gastroenterology. 2018;154(4): 897-905.e1. doi:10.1053/j.gastro.2017.11.004

43. Dominguez-Valentin $M$, Sampson JR, Seppälä TT, et al. Cancer risks by gene, age, and gender in 6350 carriers of pathogenic mismatch repair variants: findings from the Prospective Lynch Syndrome Database. Genet Med. 2020;22(1):15-25. doi:10.1038/s41436-019-0596-9

44. Wild CP. Complementing the genome with an "exposome": the outstanding challenge of environmental exposure measurement in molecular epidemiology. Cancer Epidemiol Biomarkers Prev. 2005;14(8):1847-1850. doi:10.1158/1055-9965.EPI05-0456

45. Dulai PS, Sandborn WJ, Gupta S. Colorectal cancer and dysplasia in inflammatory bowel disease: a review of disease epidemiology, pathophysiology, and management. Cancer Prev Res (Phila). 2016;9(12):887-894. doi:10.1158/19406207.CAPR-16-0124

46. Wong $\mathrm{SH}, \mathrm{Yu}$ J. Gut microbiota in colorectal cancer: mechanisms of action and clinical applications. Nat Rev Gastroenterol Hepatol. 2019; 16(11):690-704. doi:10.1038/s41575-019-0209-8

47. Brennan CA, Garrett WS. Gut microbiota, inflammation, and colorectal cancer. Annu Rev Microbiol. 2016;70:395-411. doi:10.1146/annurevmicro-102215-095513

48. Hidayat $K$, Yang CM, Shi BM. Body fatness at an early age and risk of colorectal cancer. Int J Cancer. 2018;142(4):729-740. doi:10.1002/ijc.31100

49. Mehta RS, Song M, Nishihara R, et al. Dietary patterns and risk of colorectal cancer: analysis by tumor location and molecular subtypes.

Gastroenterology. 2017;152(8):1944-1953.e1. doi:10. 1053/j.gastro.2017.02.015

50. Hofseth LJ, Hebert JR, Chanda A, et al. Early-onset colorectal cancer: initial clues and current views. Nat Rev Gastroenterol Hepatol. 2020;17(6):352-364. doi:10.1038/s41575-019-0253-4

51. Liu PH, Wu K, Ng K, et al. Association of obesity with risk of early-onset colorectal cancer among women. JAMA Oncol. 2019;5(1):37-44. doi:10.1001/ jamaoncol.2018.4280

52. Renehan AG, Flood A, Adams KF, et al. Body mass index at different adult ages, weight change, and colorectal cancer risk in the National Institutes of Health-AARP Cohort. Am J Epidemiol. 2012;176 (12):1130-1140. doi:10.1093/aje/kws192 
53. Dik VK, van Oijen MG, Smeets HM, Siersema PD. Frequent use of antibiotics is associated with colorectal cancer risk: results of a nested case-control study. Dig Dis Sci. 2016;61(1) 255-264. doi:10.1007/s10620-015-3828-0

54. Boursi $B$, Haynes $K$, Mamtani R, Yang $Y X$ Impact of antibiotic exposure on the risk of colorectal cancer. Pharmacoepidemiol Drug Saf. 2015;24(5):534-542. doi:10.1002/pds.3765

55. Kaur K, Saxena A, Debnath I, et al. Antibiotic-mediated bacteriome depletion in $\mathrm{Apc}^{\mathrm{Min} /+}$ mice is associated with reduction in mucus-producing goblet cells and increased colorectal cancer progression. Cancer Med. 2018;7 (5):2003-2012. doi:10.1002/cam4.1460

56. Hattori $N$, Niwa $T$, Ishida $T$, et al. Antibiotics suppress colon tumorigenesis through inhibition of aberrant DNA methylation in an azoxymethane and dextran sulfate sodium colitis model. Cancer Sci. 2019;110(1):147-156. doi:10.1111/cas.13880

57. Gaines S, Shao C, Hyman N, Alverdy JC. Gut microbiome influences on anastomotic leak and recurrence rates following colorectal cance surgery. Br J Surg. 2018;105(2):e131-e141. doi:10 1002/bjs.10760

58. Scott AJ, Alexander JL, Merrifield CA, et al. International Cancer Microbiome Consortium consensus statement on the role of the human microbiome in carcinogenesis. Gut. 2019;68(9): 1624-1632. doi:10.1136/gutjnl-2019-318556

59. Sears CL, Pardoll DM. Perspective: alpha-bugs their microbial partners, and the link to colon cancer. J Infect Dis. 2011;203(3):306-311. doi:10. 1093/jinfdis/jiq061

60. Hwang I, Park YJ, Kim YR, et al. Alteration of gut microbiota by vancomycin and bacitracin improves insulin resistance via glucagon-like peptide 1 in diet-induced obesity. FASEB J. 2015;29 (6):2397-2411. doi:10.1096/fj.14-265983

61. Islami F, Goding Sauer A, Miller KD, et al. Proportion and number of cancer cases and deaths attributable to potentially modifiable risk factors in the United States. CA Cancer J Clin. 2018;68(1):31-54 doi:10.3322/caac. 21440

62. Zaborowski AM, Murphy B, Creavin B, et al. Clinicopathological features and oncological outcomes of patients with young-onset rectal cancer. Br J Surg. 2020;107(5):606-612. doi:10. 1002/bjs.11526

63. Kolarich A, George TJ Jr, Hughes SJ, et al. Rectal cancer patients younger than 50 years lack a survival benefit from NCCN guideline-directed treatment for stage II and III disease. Cancer. 2018; 124(17):3510-3519. doi:10.1002/cncr.31527

64. Le DT, Uram JN, Wang $\mathrm{H}$, et al. PD-1 blockade in tumors with mismatch-repair deficiency. N Engl J Med. 2015;372(26):2509-2520. doi:10.1056/ NEJMoa1500596

65. Montecino-Rodriguez E, Berent-Maoz B Dorshkind K. Causes, consequences, and reversal of immune system aging. J Clin Invest. 2013;123(3): 958-965. doi:10.1172/JCI64096

66. Peterse EFP, Meester RGS, Siegel RL, et al. The impact of the rising colorectal cancer incidence in young adults on the optimal age to start screening: microsimulation analysis I to inform the American Cancer Society colorectal cance screening guideline. Cancer. 2018;124(14):2964-2973. doi:10.1002/cncr.31543 